This is an electronic reprint of the original article. This reprint may differ from the original in pagination and typographic detail.

Author(s): Lipiäinen, Heini; Karjaluoto, Heikki; Nevalainen, Marjo

Title: Digital channels in the internal communication of a multinational corporation

Year: $\quad 2014$

Version:

Please cite the original version:

Lipiäinen, H., Karjaluoto, H., \& Nevalainen, M. (2014). Digital channels in the internal communication of a multinational corporation. Corporate Communications: An International Journal, 19(3), 275-286. https://doi.org/10.1108/CCIJ-07-2012-0050

All material supplied via JYX is protected by copyright and other intellectual property rights, and duplication or sale of all or part of any of the repository collections is not permitted, except that material may be duplicated by you for your research use or educational purposes in electronic or print form. You must obtain permission for any other use. Electronic or print copies may not be offered, whether for sale or otherwise to anyone who is not an authorised user. 


\title{
Digital channels in the internal communication of a multinational corporation
}

\author{
Lipiäinen, H., Karjaluoto, K., \& Nevalainen, M. 2014 \\ Corporate Communications: An International Journal 19 (3), 275 - 286.
}

\begin{abstract}
Purpose: To examine how digital communication tools are used for internal communication (IC) in multinational corporations (MNCs). Specifically, the study illustrates the role of digital channels in IC, the benefits they bring and the difficulties involved in using them.
\end{abstract}

Design/methodology/approach: This research features a single-case study focusing on a listed Finnish multinational industrial corporation with a long history. Data for the study come from semi-structured theme interviews and a workshop in which the results were discussed.

Findings: Digital IC tools are able to facilitate IC in MNCs, although some challenges may arise in relation to planning their utilization. Related to the role of digital channels in IC, these findings highlight the importance of face-to-face channels in everyday internal communication and the role of digital channels as more formal communication channels.

Research limitations: This paper focuses on a single organization. Additional research would be required to attain generalizable results.

Practical implications: The effective use of new digital communication tools requires common guidelines across all areas of an MNC. Despite the great potential of new tools, the importance of face-to-face communication should not be ignored.

Originality/value: Most of the research on IC in MNCs was conducted before the digital communications era. Recent advances in information technology have created new challenges and opportunities for IC.

Article type: Research paper

Keyword(s): Internal communication, digital media, social media, multinational corporations 


\section{Introduction}

The existing research on internal communications (IC) in multinational corporations (MNCs) $^{[1]}$ was mostly conducted before the digital communications era. The literature has examined IC from the perspective of how to use traditional communications channels effectively and the skills needed for efficient communication (Charles and Marschan-Piekkari, 2002; Du-Babcock and Babcock, 1996; Tucker et al., 1996; Quible et al., 1996). Recent advances in information technology have created new challenges in managing and facilitating IC, but along with those challenges come opportunities. Nowadays, it is difficult to choose between all the channels provided by the new technology (Quirke, 2008). Many organizations are utilizing new digital communication channels, such as social media, in their IC; however, research indicates that social media (e.g. blogs, communities) in particular is seen as more important for external communications, its main objectives being branding and creating awareness (Järvinen et al., 2012; Lee et al., 2005; Michaelidou et al., 2011; Scott, 2010). The fact that research related to digital media has focused more on external communication seems to suggest an interest in research related to the use of digital tools in IC. According to a Delphi study of IC among the leaders of the Federation of European Business Communicators Associations, the most topical interest is in new internal digital (including social) media (Verčič et al., 2012). Internal digital communications are increasingly being adopted by corporations (e.g. Salesforce.com's 'Chatter'; Microsoft's 'Yammer'; the BBC's intranet, which features blogs, videos and staff interviews; IBM's internal social network 'IBM Connections' and Wärtsilä's 'Ask the Doers') to communicate with employees, facilitate two-way conversations, gather ideas, give feedback, trigger greater engagement and motivation and, overall, encourage employees to contribute to company strategy.

For this reason, it is vital to examine how digital communication tools are used for IC in a multinational corporation. Specifically, the article attempts to illustrate the role of digital channels in IC, their benefits and the difficulties of using them. Hence, this study responds to calls for research on IC in the digital environment. The remainder of the article is organized as follows. The next section presents the literature review, facilitating an understanding of digital tools in IC. This is followed by a discussion of the methodology used in this study and its empirical results. Finally, the findings and implications are discussed and explained, followed by an assessment of the limitations and finally by suggestions for further research.

\section{Digital communication channels in IC}

Traditionally, companies have used tools such as corporate TV, wall posters and corporate magazines, all of which are one-way broadcasting (one-to-many) tools, for IC. Today, computer-mediated exchange and shared electronic resources have an enormous potential to encourage employee participation in practice (Beirne and Cromack, 2009). The literature classifies new digital communications channels in various ways. Recently, the terms "social media" (e.g. Kaplan and Haenlein, 2010) and "new media" (Hennig-Thurau et al., 2010) have been used to describe a changing communications landscape. Kaplan and Haenlein (2010) categorize social 
media into six types: collaborative projects, blogs, content communities, social networking sites, virtual game worlds and virtual social worlds.

In terms of internal social media use, the most important element seems to be collaborative projects enabling simultaneous content creation by a number of employees. Collaborative projects include wikis and social bookmarking applications enabling group-based collation and rating of web links or media content (Kaplan and Haenlein, 2010). Intranet portals have become popular as a result of increasing pressure on businesses to digitalize and integrate IC (Neill and Richard, 2012). At its best, an intranet contains everything individuals need to do their jobs like updates, housekeeping materials and newsletters from top management (Muller, 2002). An intranet also permits colleagues to communicate with each other regardless of location or which hardware and operating systems they use (Mosbeh and Soliman, 2008). In addition to an intranet's powerful ability to facilitate information transfer, it can be used to measure performance and provide accurate information on critical strategic issues to support managers' strategic decision-making (Denton, 2006).

However, intranets will not directly lead to better inter-functional coordination if they are not designed properly, or if employees do not understand the full benefits of using them (McNaughton et al., 1999). In fact, most employees seem to lack the time to browse websites for information (White et al., 2010). As Denton (2006) remarks, besides the need for intranets, there is a crucial need for technology that helps employees and managers make sense of the massive amount of data in circulation. An intranet is only likely to become efficient in organizations where the management dares to empower employees to be more active in the design of the information landscape (Stenmark, 2003).

Blogs can also be useful in IC as a way of keeping employees updated. Blogs are personal web journals where authors publish their thoughts and ideas and readers can comment on the content (De Pelsmacker et al., 2007, p. 515). Blogs are a useful way for companies to influence public conversation by contributing accurate information. Smudde (2005) has noted that the communication style of corporate blogs is not as informal as that of the non-corporate form, but the presence of top management means they seem appealing and useful. Readers are keen on hearing the 'inside view from the top'. Many companies (e.g., Microsoft, Sun) also encourage their employees to blog on their official sites (Kelleher and Miller, 2006). As for the new media tools used by many on a daily basis, social networking sites such as Facebook have been used far more frequently for the purpose of external communications; however, many organizations also use them in informal IC.

Despite the new social tools available for use in IC, email remains the most commonly used digital communication medium in today's organizations. It is a very popular, cheap, easy and quick way to communicate. However, the ability to distribute information quickly and easily can lead to information overload and an overreliance on technology-based channels at the expense of face-to-face communication (Hewitt, 2006). The debate around the merits of email as a communication channel continues. Asynchrony of communication can cause frustration, and the approach taken to a problem can easily move from mild to more aggressive strategies (Friedman and Currall, 2003). Stevens and McElhill (2000) for 
example, have noted that written communication is rarely the best way to convey a message or to motivate employees. Hallowell (1999, p. 60) points out that the use of electronic communication channels has distanced employees from each other and from the organization to which they belong. However, emails have beneficial features like reviewability referring to the attribute that each participant in the email conversation has a record of others' comments, and revisability referring to the option to check and correct a message before sending, that are unavailable in verbal communication (Friedman and Currall, 2003).

Internal instant messaging (IM) also provides opportunities for quick and efficient IC. That said, IM carries the risk of viruses and spyware, and of employees spending excessive time chatting to co-workers (Wilkins, 2007; Quan-Haase, 2008). Like email, IM makes it impossible to observe the speaker's demeanour, body language or to convey intonation, which can easily lead to misunderstandings. In addition, there is a problem of timing in relation to actions and reactions; for example, agreeing or disagreeing with aspects of the conversation always happens a little later via IM than in face-to-face communication (Wolk, 2002). However, IM is quick and cheap but also synchronous, and it is possible to be in contact with multiple individuals at the same time (Quan-Haase, 2008). The biggest benefit involves presence. IM can be less formal, more questions regarding clarification can be raised and it is easier to check that the other party is on the same wavelength before proceeding (Morris et al., 2002). Morris et al. (2002) suggest that IM would be a better channel than email for creating a more social atmosphere.

Despite the vast potential of these new tools, they are useless if the media used to carry the message is not acceptable to employees (Welch, 2012). The effectiveness of communication depends on both the sender's and receiver's familiarity with particular communication medium codes and conventions (Belch and Belch, 2007). It seems that traditional communication is still the most favoured IC medium among employees. For example, Friedl and Verčič (2011) found that representatives of generation Y (born since 1980) prefer traditional IC channels at work, while having a strong preference for social media in their private lives. Several studies (e.g. Stein, 2006; White et al., 2010) report that face-to-face communication is the preferred IC channel owing to its richness; face-to-face communication enables straight feedback and the transmission of information in a more personal manner than other communication tools. When people are in regular face-to-face contact, relationships start to evolve, and when people know each other, it is easier to communicate (Grunig et al., 2002). However, it seems that employees prefer different media for different sorts of information (Woodall, 2006). Emails are considered useful for quick updates and announcements, and websites (or the intranet) are useful as archives for information to be retrieved as needed (White et al., 2010).

\section{Methodology}

\subsection{The single-case study as a research strategy}

This research uses a single-case study as a research strategy (Yin, 2003). Single-case studies have been found to be extremely successful when presented in the developmental stages of a field of study (Eisenhardt, 1991). The topic of this research is fresh and timely, supporting the justification for the single-case research method. 
The selected case company is a listed Finnish multinational industrial corporation with a long history. It is headquartered close to Helsinki and has its main production plants in Europe and the USA, from where it provides products, technologies and services to customers worldwide. A recent acquisition has elevated the company to the position of global leader in its industry, with sales of around $€ 12$ billion and more than 19,000 employees worldwide.

\subsection{Research methods and data analysis}

In this study, the unit of analysis is the usage of digital tools for IC in an MNC, and occurs at corporate level. Data for the study come from nine semi-structured theme interviews selected purposefully (see Table 1) and from a workshop in which the results of the interviews were presented by two researchers and discussed with eight representatives responsible for developing IC in the firm. A qualitative setting makes it possible to understand latent, underlying or non-obvious issues (Miles and Huberman, 1994 p.10). A semi-structured interview is a suitable method for developing an understanding of how managers perceive their job and environment (Qu and Dumay, 2011). The interviewees had been involved in the international affairs of the organization for several years and were familiar with its IC practices. These nine were the primary informants, chosen because of their direct and handson experience with the company's IC and their willingness to share their experiences. The respondents based in Finland were interviewed face-to-face, and the others by telephone. The interviews were conducted during January and February 2010. The timeframe of the interviews ranged between 20 and 45 minutes; five were conducted in Finnish and four in English.

\begin{tabular}{l|l|l}
\hline Interviewee & Position & Duration of employment \\
\hline John & Managing Director & 20 years \\
Michael & Technology and Development Manager & 5 years \\
Frank & Product Manager & 28 years \\
Han & Sales Director & 20 years \\
Kenneth & Product and Project Manager & 39 years \\
Mark & Sales Manager & 9 years \\
Nick & Site Manager & 5 years \\
Steve & Sales Manager & 6 years \\
Zach & Sales Manager & 5 years \\
\hline
\end{tabular}

Note: All participants are key managers in the corporation with decision-making responsibilities. They have been assigned pseudonyms.

Table 1 Study sample

The interviews were transcribed and read through several times before more careful analysis was undertaken. That analysis employed thematization consisting of the three-step procedure advocated by Miles and Huberman (1994, p.10) that includes data reduction, data display and the drawing/verification of conclusions. For data reduction, all the material was organized under the same themes discussed in the interviews (IC in general: challenges, role, formal/informal communication etc.; intercultural communication: challenges, influence on IC etc.; and channels used for IC: digital channels, preferred channels, channels usage, challenges, and 
opportunities). For data display, each theme was analysed individually; matrices were constructed that facilitated the concise assembly of information and drawing conclusions. The data was also organized inductively according to the digital tools brought up in the interviews. First, the tools used for IC were identified. Next, we collated the interviewees' descriptions of the role and usage of each digital tool and also their advantages and the issues with them. Thick descriptions of each channel's usage were written to create an overall picture of how channels were used. Next, the advantages and issues surrounding use and suggested solutions to the issues were collected and organized in a table. Finally, to perform the data verification, we synthesized our interpretations of the themes and presented them in a workshop for the case company's representatives to review. The workshop also discussed the implications of the findings for the case firm, and confirmed that the results obtained by the researchers were sound in terms of managerial relevance.

In this research, the interviewees were employees of the company, which aroused some specific ethical problems in terms of privacy, confidentiality and anonymity. People familiar with a case are nearly always able to identify who is being interviewed (Miles and Huberman, 1994, p. 293) and that was also likely in this research Protecting the employees' privacy was especially important since the results were presented in the workshop. This was one of the main reasons why the results were not analysed and compared in smaller segments.

\section{Results}

Like almost all organizations, the case MNC employs a wide range of different IC channels. Among the often-used non-digital channels, basic noticeboards and notes on the dining tables were used internally to pass on routine news. However, most information in the case corporation is shared via online channels, with the intranet and email playing a significant role. The company strategy states a desire to invest in communication methods employing open dialogue, which accords with the emphasis on digital channels in its communications.

\subsection{Digital channels in IC}

\subsubsection{The intranet}

The case company's intranet appears to be its main internal information-sharing channel. The intranet carries news, announcements and information concerning products and markets (price lists, forecasts, charts). The intranet in the case company runs on two levels: the first, organization-wide level is open to everyone; the second, the operational portal, extends to incorporate smaller sites (e.g., local sites, business unit sites), which are in many cases restricted to certain units within the corporation. Several respondents described difficulties in utilizing the intranet. Participants often said that the problem with the intranet is its reliance on employees finding information. Some interviewees said they use the intranet daily, but some said they did not really have time to search for information there. The popularity of the intranet varied between units some participants spoke of minimal use and infrequent updating. The intranet was considered a very good tool if there were sufficient resources to keep it updated and coherent. 
Han: I use the intranet in my cluster, we share documents and information. But I don't have a clue how often people go there. And we have restricted resources to generate content.

Mark: The intranet could be used more often and more efficiently if it was in order and up to date. It's one of the most critical issues. We don't have enough resources at the moment.

In addition, most participants wanted better interactivity on the intranet, and the lack of interactivity caused uncertainty among the employees. The intranet is open to comment on stories and news, and has a "leave a comment" function that allows dialogue within it. However, the respondents said dialogue usually ends when an employee has commented on something: that is, the author of an announcement (for example, the $\mathrm{CEO}$ ) rarely responds to any comments.

Han: When there is an announcement anyone can comment, and I think it's good. But the problem is that many times people comment in a negative sense and usually the writer of the article or a representative doesn't reply... They should be more active, interactive.

\subsubsection{Email}

Emails were preferred because they are quick, cheap and easy to store and review later. On the negative side, the interviewees felt that the amount of emails received had grown excessively while, at the same time, their importance had diminished. Response times were sometimes too long and people did not always understand that a swift reply was needed. However, employees often felt easier to send an email than to ask for a face-to-face discussion or make a phone call. In consequence, as Frank described:

Frank:"I think generally we as a company have gone more into internal emails between people in the organization where we are losing the art of verbal communication".

The interviewees thought that diminished feedback and minimal social cues increase misunderstandings. In emails, people can appear to be sterner than they really are. Several participants stressed that personal characteristics have an effect on how messages are received and handled: messages and communication should be altered according to the receiver, and attention should be paid to the channel used and the content of the message.

Mark: It [email] can be greatly misused by the sender and the receiver. If the message is not understood, the email might not be compiled well enough or there may be other reasons why the message is not received. It can be just misunderstood and it can cause a lot of harm.

In addition, a number of respondents had a negative attitude towards group emails. Several pointed out that, when receiving group emails, it was unclear who would be responsible for taking the necessary action. Since the recipients did not know who should reply, finally nobody did. In addition, many organization-wide mass emails were considered boring and repetitive.

\subsubsection{Instant messaging}


Another internet-driven communication tool utilized in the corporation is IM, which is built into the email software. Only (the youngest) two participants, however, mentioned IM, suggesting that it is not a widely used communication tool and even they did not used it routinely. They mentioned that they would often avoid it because their IM conversation was not documented. They did however report that IM could provide a convenient means to check if another person was available.

Steve: I have tried to avoid it because it leaves no documentation of what has been agreed. And I am not used to using it so I don't remember to turn it on, and then again I forget to turn it off.

\subsubsection{Blogs}

It was surprising that when asked whether the case corporation utilizes blogs in IC, around half of the respondents said yes while the other half said no. Some said that there used to be a corporate blog but it was probably no longer there, as it did not work; people got bored of reading, writing or commenting on the blog. Some said that there was still a blog but not many people read it. Others said that there was no corporate blog, but there definitely should be one. In reality, at the time of the study, the corporation had a blog on the intranet, but it was serving merely as a news source, albeit with the option to comment on the stories. The attitudes towards blog use in IC varied between two extremes. On the negative side, respondents described blogs as the worst channel to use in IC:

Mark: Yes, we have a blog, but I must say that it is one of the worst channels. I am not convinced at all that there is any benefit in it. Of course, it can be good if somebody has the time to write and if somebody has the time to read it. But I would argue that it is a very ineffective channel.

On the positive side, a blog was seen as the best way to attract readers' interest:

Han: Yes a blog that is something I'd like to see. Where we would be told what is being done and what is happening, especially by the top management. Often people feel that the top management is very remote and we don't really see them, decisions just get made.

\subsection{Discussion of the results}

The main advantages and challenges caused by digital channels are summarized in Table 2 in terms of internal communication in multinational corporations with suggested solutions elicited in the interviews. 


\begin{tabular}{|c|c|c|c|}
\hline & $\begin{array}{l}\text { Advantages of digital } \\
\text { tools }\end{array}$ & $\begin{array}{l}\text { Challenges caused by digital } \\
\text { channels }\end{array}$ & Suggested solutions \\
\hline $\begin{array}{l}\text { Internal } \\
\text { communication } \\
\text { in } \\
\text { multinational } \\
\text { corporations }\end{array}$ & $\begin{array}{l}\text { - Ease and speed of the } \\
\text { tools } \\
\text { - Possibility to store } \\
\text { information } \\
\text { - Makes it possible to } \\
\text { communicate worldwide } \\
\text { - Makes it possible to } \\
\text { work and communicate } \\
\text { flexibly (i.e. the intranet } \\
\text { can be accessed at any } \\
\text { time) } \\
\text { - Ability to use new tools } \\
\text { (e.g. blogs) to } \\
\text { communicate company } \\
\text { spirit }\end{array}$ & $\begin{array}{l}\text { - Lack of clarity and different } \\
\text { habits in using different digital } \\
\text { channels } \\
\text { - Information overload } \\
\text { - Diminished feedback and } \\
\text { minimal social cues } \\
\text { - Lack of email writing skills } \\
\text { - Pronounced direct, provocative } \\
\text { and aggressive communication } \\
\text { style in digital channels } \\
\text { - Communication in digital } \\
\text { channels is task-oriented and } \\
\text { formal } \\
\text { - Formal communication was } \\
\text { felt to hinder the development } \\
\text { of personal relationships }\end{array}$ & $\begin{array}{l}\text { - Need for general } \\
\text { guidelines and } \\
\text { management of how to } \\
\text { use different tools (e.g. } \\
\text { rules on how to use the } \\
\text { intranet) } \\
\text { - Need to get to know co- } \\
\text { workers } \\
\text { - Good relations help one } \\
\text { try one's best to } \\
\text { overcome differences } \\
\text { - Need for face-to-face } \\
\text { communication }\end{array}$ \\
\hline
\end{tabular}

Table 2 Advantages, issues and suggested solutions in terms of internal communication in multinational corporations

The use of digital tools brought several advantages for the case company. It was stated that the digital tools were easy and quick to use, which made communication easier. In addition, the reviewability and revisability of digital tools were identified as their greatest benefits. Benefits related to intercultural communication included digital channels facilitating communication with people around the world and in different time zones. Internal digital channels were noted to increase the flexibility of work. It became apparent that the MNC would face major issues in implementing effective IC if it lacked a capability to communicate digitally. The case company's employees also mentioned the potential of corporate blogs to convey company spirit. Despite the emphasis on digital tools, a strong desire for face-to-face communication emerged from the interviews.

The major challenges to the usage of digital internal channels related to a lack of clarity and people having different habits. For example, communication across functions was hampered by difficulties finding the right person to talk to about a particular issue. Participants also said that if the message was sent to wrong person, response times were longer and feedback was not provided efficiently enough. As a result, people often had to use two or even three communication channels when contacting people from other functions. Typically, an email would be sent first and when a reply did not come, a follow-up phone call would be made.

Mark: Problems occur especially in communication between marketing and production. I work in the middle so the difference is very noticeable. Viewpoints are different, attitudes are different. Who knows what, who has information about the issue and who thinks this and who thinks that? It is just that, difficulty communicating. When we don't understand enough, it is hard.

Communication through digital channels was seen to be task-oriented and formal. Formal communication was felt to hinder the development of personal relationships, particularly across corporate functions. The situation is unlikely to be 
helped when the channel of communication used is email. Our findings highlight the importance of informal face-to-face communication, as the informants were unanimous in stating that it is easier to build trusted relationships face-to-face than via digital channels or the telephone. Where face-to-face communication was not feasible, the telephone was regarded as the second-best channel. The case corporation constantly arranges telephone conferences between different units and has piloted video conferences.

Steve: Personal contacts, when you are doing something you haven't done before, are golden.

John: Face-to-face communication is the best channel. Then you are able to commit the individual and you can see their reaction. In all the other methods, you can't personally see when you look in the individual's eye that he is serious when he says that the job will be done... We are such a small unit so we always aim to verbally share all the information we consider important.

Contrary to expectations, cultural differences were not highlighted during the interviews. A few anecdotes about cultural differences were related but overall culture did not seem to have too great an effect. This might be because the interviewees had a quite international mind-set and experience of different cultures - in general, people in the organization are in daily contact with people with various cultural backgrounds.

\section{Conclusion and implications}

The purpose of this study was to examine how digital communication tools are used for IC in an MNC. It specifically examined the role of digital channels, and both the benefits and issues they bring. The findings of the study indicate that digital communication tools can be widely used and will facilitate IC in an MNC, although they can be some challenges around planning their utilization.

\subsection{Theoretical contributions}

The study contributes to the IC literature through its examination of an underresearched area, namely the usage of digital communication channels for IC and the role of digital communications channels in IC. The findings call for better organization of the new tools and their usage. This is an important aspect to bear in mind, especially as the number of potential digital IC channels is growing rapidly and business leaders are showing interest in these new tools (e.g. Verčič et al., 2012). The introduction of new technology should be considered carefully, despite the new, easily available, tempting options available to address MNCs' IC challenges. It is important to remember that communication effectiveness depends on both the sender's and the receiver's familiarity with the codes and conventions of a particular medium (Belch and Belch, 2007). For example, for younger employees, using an IM program seemed to be something they were familiar with and made communication easier. The use of IM among younger employees found in this study is in line with the notion that a medium is more likely to be used if it is accepted by, and familiar to, the employee; if not, the new tool will be useless (Welch, 2012). 
In answering our research question about the role of digital channels in IC, these findings highlight the importance of face-to-face channels in everyday informational internal communication and the role of digital channels (including email) in more formal communication. This study therefore confirms the notion that face-to-face communication is still the preferred channel for IC (e.g. Stein, 2006; White et al., 2010) owing to its richness and clarity. Face-to-face communication was seen to be important in creating relationships and thus facilitating work. This is also consistent with the notion that when people are in regular face-to-face contact, relationships develop, and it becomes easier to communicate (Grunig et al., 2002). The role of digital IC channels as more formal communication channels is line with when comparing digital internal channel usage with digital channels used to communication externally, in which the main objectives have thus far been branding and creating awareness (Järvinen et al., 2012; Lee et al., 2005; Michaelidou et al., 2011; Scott, 2010). The most common objectives are informative in nature. This is an important notion when discussing goal setting for digital IC tools. The digital channels studied in this research are more likely to be suitable for developing awareness and understanding than for engendering commitment and a sense of belonging, which have also been mentioned as key goals of IC (see Welch and Jackson, 2007).

\subsection{Managerial implications}

Digital channels provide several benefits for MNCs and, given the increase in globalization and market liberalization, will have an even more important role in the future. Despite the charm and novelty of the new digital tools and their great ability to solve some of the IC problems facing MNCs, their role within an organization's IC toolbox should be considered carefully. New digital channels require management and clear common guidelines across the company. When a company adopts new digital tools, it should be made clear to everyone how different tools are used within the organization and who is responsible for what.

Despite the availability of new digital tools, is it important to remember that face-to-face communication and telephone conversation are still superior to alternatives such as email, IM and intranet use. Of course, face-to-face contact is not always possible or practical in an MNC, but ways in which people may communicate face-to-face through digital channels could be found. With regard to facilitating informal communication, it may well be that younger people are more familiar with using written, digitally mediated communication for informal communication; but it will be many years before an organization is entirely staffed by representatives of generation $\mathrm{Y}$ and beyond. Informal events where employees can meet should not be disregarded. Perhaps other, more unofficial platforms (such as Facebook) might offer potential channels through which to share ideas and feelings and, hence, be more suitable platforms for the promotion of commitment and a sense of belonging within companies in the future.

\subsection{Limitations and further research}


Our results must be evaluated in light of certain key limitations. First, they are based on a single-case study and hence cannot be generalized. Second, as all the interviewees were white-collar workers and their numbers were limited, there is a need for deeper analysis of IC in multinational corporations. Future studies could for example examine the differences between blue-collar workers and white-collar workers, supposing that blue-collar workers also have similar access to new IC tools, which was not the case in the present study. It would be useful to examine whether there are many corporations facing problems in their IC, and whether one reason may be the increased use of electronic communication. In this way, solutions and best practice could be identified and shared with other corporations.

In the future, it would be useful to study employees' expectations of IC and which tools they prefer to use. These findings would guide companies in selecting appropriate digital tools for communication. It would also be beneficial to study the differences between older and younger employees and their IC-channel preferences.

\section{References}

Beirne, M. and Cromack, C. (2009), “Managing creative coalition's: Reflections on the social side of services innovation", European Management Journal, Vol. 27 No. 2, pp. 83-89.

Belch, E. and Belch, M.A. (2007), Advertising and promotion: an Integrated marketing communications perspective, 7th ed., McGraw-Hill/Irwin, New York, NY.

Charles, M. and Marschan-Piekkari, R. (2002), "Language training for enhanced horizontal communication: A challenge for MNCs", Business Communication Quarterly, Vol. 65 No. 2, pp. 9-29.

De Pelsmacker, D., Geuens M. and Van den Bergh, J. (2007), Marketing communications. A European perspective, 3rd ed., Prentice Hall, Harlow.

Denton, K. (2006),"Strategic intranets: the next big thing?", Corporate Communications: An International Journal, Vol. 11 No. 1, pp. 5-12.

Du-Babcock, B. and Babcock, R.D. (1996),"Patterns of expatriate-local personnel communication in multinational corporations", The Journal of Business Communication, Vol. 33 No. 2, pp. 141-165.

Eisenhardt, M. (1991), "Better stories and better constructs: The case for rigor and comparative logic", Academy of Management review, Vol. 16 No. 3, pp. 620-627.

Friedl, J. and Verčič, A.T. (2011), "Media preferences of digital natives' internal communication: A pilot study", Public Relations Review, Vol. 38 No. 1, pp. 84-86.

Friedman, R. and Currall, S. (2003), "Conflict escalation: Dispute exacerbating elements of e-mail communication", Human Relations, Vol. 56 No. 11, pp. 13251347.

Grunig, L., Grunig, J. and Dozier, D. (2002), Excellent public relations and effective organizations: A study of communication management in three countries, Lawrence Erlbaum Associates. Hillsdale, NJ.

Hallowell, E. (1999), “The human moment at work”, Harvard Business Review, Vol. 77 No. 1, pp. 58-66.

Hennig-Thurau, T., Malthouse, E.C., Friege, C., Gensler, S., Lobschat, L., Rangaswamy, A. and Skiera, B. (2010), "The impact of new media in consumer relationships", Journal of Service Research, Vol. 13 No. 3, pp. 311-330. 
Hewitt, P. (2006), "Electronic mail and internal communication: A three-factor model", Corporate Communications: An International Journal, Vol. 11 No. 1, pp. 78-92.

Järvinen, J., Töllinen, A., Karjaluoto, H. and Jayawardhena, C. (2012),"Digital and social media marketing usage in B2B industrial section", Marketing Management Journal, Vol. 22 No. 2, pp. 102-117.

Kaplan, A.M. and Haenlein, M. (2010), "Users of the world, unite! The challenges and opportunities of Social Media", Business Horizons, Vol. 53 No. 1, pp. 59-68.

Kelleher, T. and Miller, B.M. (2006), "Organizational blogs and the human voice: relational strategies and relational outcomes", Journal of Computer-Mediated Communication, Vol. 11 No. 2, pp. 359-414.

Lee, S., Hwang, T. and Lee, H.H. (2005), "Corporate blogging strategies of the Fortune 500 companies", Management Decision, Vol. 44 No. 3, pp. 316-334.

McNaughton, R., Quickenden, P., Matear, S. and Gray, B. (1999), “Intranet adoption and inter-functional co-ordination", Journal of Marketing Management, Vol. 15 No. 5, pp. 387-403.

Michaelidou, N., Siamagka, N.T. and Christodoulides, G. (2011), “Usage, barriers and measurement of social media marketing: An exploratory investigation of small and medium B2B brands", Industrial Marketing Management, Vol. 40 No. 7, pp. 1153-1159.

Miles, M.B. \& Huberman, A.M. (1994), Qualitative data analysis, 2 ed., Sage Publications, Thousand Oaks, London.

Morris, M., Nadler, J., Kurtzberg, T. and Thompson, L. (2002), "Schmooze or lose: Social friction and lubrication in e-mail negotiations", Group Dynamics: Theory, Research, and Practice, Vol. 6 No. 1, pp. 89-100.

Mosbeh, R. and Soliman, K. (2008), "An exploratory analysis of factors affecting users' adoption of corporate intranet", Management Research News, Vol. 31 No. 5, pp. 375-385.

Muller, N.J. (2002), "Challenges of intranet management", in Purba, S. (Ed.), New Directions in Internet Management: Best Practices Series, Auerbach Publications, Boca Raton, FL, pp. 203-221.

Neill, W. D. and Richard, J. E. (2012), "Intranet portals: Marketing and managing individuals' acceptance and use", Australasian Marketing Journal, Vol. 20 No. 2, pp. 147-157.

Qu, S.Q. \& Dumay, J. (2011), "The qualitative research interview", Qualitative Research in Accounting \& Management, Vol. 8 No. 3, pp. 238-264.

Quan-Haase, A. (2008), "Instant messaging on campus: Use and integration in university students everyday communication", The Information Society, Vol. 24 No. 2, pp. 105-115.

Quible, Z. K., Johnson, M. H. and Mott, D. L. (1996), Business communication: principles and applications, Prentice-Hall, Englewood Cliffs, NJ.

Quirke, B. (2008), Making the connections: Using internal communication to turn strategy into action, 2nd ed., MPG Books Ltd., Great Britain.

Scott, D. M. (2010), The new rules of marketing and PR: How to use social media, blogs, news releases, online video, and viral marketing to reach buyers directly, 2nd ed., John Wiley and Sons Inc, Hoboken, N.J. 
Smudde, P. (2005), "Blogging, ethics and public relations: A proactive and dialogic approach", Public Relations Quarterly, Vol. 50 No. 3, pp. 34-38.

Stein, A. (2006), "Employee communications and community: An exploratory study employee communications and community", Journal of Public Relations Research, Vol. 18 No. 3, pp. 249-264.

Stenmark, D. (2003), “Knowledge creation and the web: factors indicating why some intranets succeed where others fail", Knowledge and Process Management, Vol. 10 No. 3, pp. 207-216.

Stevens, G. and McElhill, J. (2000), “A qualitative study and model of the use of email in organisations", Internet Research: Electronic Networking Applications and Policy, Vol. 10 No. 4, pp. 271-283.

Tucker, M. L., Meyer, G. D. and Westerman, J. W. (1996), “Organizational communication: Development of internal strategic competitive advantage", Journal of Business Communication, Vol. 33 No. 1, pp. 51-69.

Verčič, A.T., Verčič, D. and Sriramesh, K. (2012), "Internal communication: Definition, parameters, and the future", Public Relations Review, Vol. 38 No. 2, pp. 223-230.

Welch, M. (2012), “Appropriateness and acceptability: Employee perspectives of internal communication", Public Relations Review, Vol. 38 No. 2, pp. 246-254.

Welch, M. and Jackson, P. (2007), "Rethinking internal communication: A stakeholder approach", Corporate Communications: An International Journal, Vol. 12 No. 2, pp. 177-198.

White, C., Vanc, A. and Stafford, G. (2010), "Internal communication, information satisfaction and sense of community: The Effect of Personal Influence", Journal of Public Relations Research, Vol. 22 No. 1, pp. 65-84.

Wilkins, J. (2007), “RU ready for IM?", The Information Management Journal, Vol. 41 No. 3, pp. 26-31.

Wolk, M. (2002), "E-mail and instant messaging retention, review, and production", Journal of Investment Compliance, Vol. 3 No. 3, pp.13-18.

Woodall, K. (2006), "The future of business communication", in Gillis, T. L. (Ed.), The IABC handbook of organizational communication: A guide to internal communication, public relations, marketing and leadership, Jossey-Bass/John Wiley, San Francisco, pp. 514-531.

Yin, R.K. (2003), Case Study Research. Design and Methods, 3ed., Sage Publications, Inc. Thousand Oaks, CA.

[1] The terms 'company' and 'corporate' are used almost synonymously in this paper, although we acknowledge that they are not exactly the same. When the term 'company' would not be appropriate or would create confusion we have used the term 'corporate'. 